\title{
Jurnal
}

\section{THE RELATIONSHIP BETWEEN STREET NETWORK MORPHOLOGY AND PERCENTAGE OF DAILY TRIPS ON FOOT AND BY BICYCLE AT THE CITY-LEVEL}

\author{
Zohreh Asadi-Shekari, Mehdi Moeinaddini*, Zahid Sultan, \\ Muhammad Zaly Shah, Amran Hamzah \\ Faculty of Built Environment, Universiti Teknologi Malaysia, 81310 \\ UTM Johor Bahru, Johor, Malaysia
}

Article history

Received

6 July 2015

Received in revised form

5 August 2015

Accepted

1 September 2015

*Corresponding author mehdi@utm.my

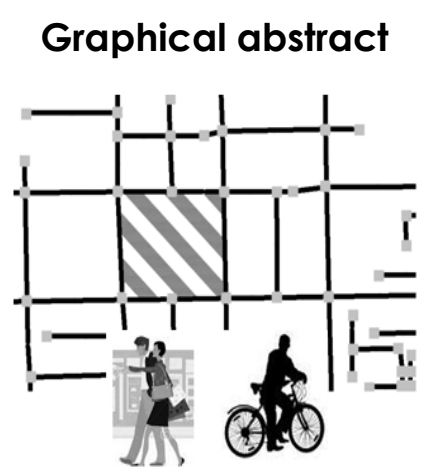

\begin{abstract}
There are various factors that affect walking and cycling in urban areas, such as density, diversity and design, but there have been few studies that examine the relationship between urban morphology factors such as street network and green travel modes (e.g., walking and cycling) at the city-level (macro-level). Thus, this paper focuses on this relationship by introducing street network morphology factors, such as blocks per area, nodes per blocks and nodes per area. The street network in this study includes interconnecting lines and points that present streets, roads, motorways, intersections and blocks. The percentage of daily trips on foot and by bicycle data that represents walking and cycling are collected from the International Association of Public Transport's (UITP) database. The blocks per area, nodes per area and the nodes per blocks are estimated by modifying and analyzing Open Street Maps (OSM). The data that are used in this study are from 30 cities in different parts of the world. The strength of the relationship in this study was found using the Pearson correlation coefficient. The results show that increase in daily trips on foot and by bicycle is correlated with increasing number of blocks per area and number of nodes per area while daily trips on foot and by bicycle has negative relationship with number of nodes per blocks. Because the urban street network is the result of macroscale planning decisions, considering the relationship between street network morphology and travel behavior can lead to better planning decisions.
\end{abstract}

Keywords: Network morphology, daily trips on foot and by bicycle, street pattern, sustainable urban transport planning

(c) 2015 Penerbit UTM Press. All rights reserved

\subsection{INTRODUCTION}

Malaysia has high rate of obesity and diabetes [1]. Based on National Health and Morbidity Survey, more than $20 \%$ of Malaysians who have 30 years old and above suffered from diabetes in 2011. Active lifestyle that includes active travel modes such as walking and cycling are associated with a lower likelihood of diabetes and obesity [2]. Urban areas with high population and a variety of activities (e.g., working, studying, and business) need to have proper plans that address the mobility and accessibility needs such as healthier travel modes [3-4].
Urban structure can affect travel behavior and the effects of urban structure on the travel behavior including walking and cycling has been investigated by various studies [e.g. 5-13]. Street networks are important urban structure indicators that affect cities form and travel behavior [14].

Street length and density are two important factors for urban street network that are considered as effective factors in various studies $[9,15]$. In addition to the street length and density, intersections are also important indicators for urban street network [16-18]. Ample studies consider a relationship between intersection density and vehicle miles travelled (VMT) [19-22]. Intersection density also can affect street 
connectivity [23-25]. More intersections that provide more connected roads can reduce travel distance and time for pedestrians and cyclists. Connected roads increase walking and cycling and decrease VMT [8, 24, 26-27].

Street patterns also can affect travel behavior since they shaped block size, block length and block density. For instance, some studies find a relationship between block size and number of walking trips [2830]. Some studies also find a relationship between street block density and VMT per household [31]. Block length also affects miles walked per person [32]. Smaller blocks can represent more roads and intersections that provide more connected and direct roads.

There are some shortcomings that prevent previous efforts to evaluate the relationship between street network morphology and percentage of daily trips on foot and by bicycle at the city-level sufficiently. Firstly, there are limited studies that focus on city-level and compare different cities in different socio-economic contexts. Secondly, intersections and block density that are important parts of the city morphology have not investigated by previous studies as street network morphology indicators and the majority of the previous studies consider these factors for connectivity indicators. Therefore, block density and intersection density are represented by polygons (blocks) per area and nodes per polygons (blocks) in this study to have network morphology indicators in addition to the connectivity factors.

Overall, this study attempts to evaluate the effects of urban street network indicators that shape street network morphology on the walking and cycling at the city-level. These effects can be used for street network design and strategies that encourage walking and cycling and reduce private car usage at the citylevel. The street network morphology in this study is represented by lines and points that include roads, streets, motorways, blocks and intersections.

\subsection{MATERIALS AND METHOD}

Eurostat database, UITP and some developed cities database are limited urban mobility data sources at the city-level. Although UITP database includes more cities and indicators than others, this database does not have enough street network morphology indicators that represent connectivity and block size. Therefore, open street maps (OSM) are used to have nodes per area, nodes per blocks and blocks per area. A node represents an intersection and a block represents an area that is surrounded by roads. Nodes per area and blocks per area represent nodes and blocks density in the study area (defined metropolitan areas by UITP). UITP database provides percentage of daily trips on foot and by bicycle. Table 1 shows the collected data from UITP and OSM. Nodes per area, nodes per blocks and blocks per area are the results of modifying and analyzing OSM data (refer Figure 1). The size of the blocks can be represented by the number of blocks per area. Nodes per blocks also can illustrate the average road density for the blocks. The type of intersection (nodes) is not considered in this macro-level study (e.g., 4-way, 3-way, interchange, etc.). However, more nodes and more routes can represent connection density and connectivity.

Table 1 Research data

\begin{tabular}{lcccc}
\hline Cities & $\begin{array}{c}\text { Percentage of daily trips } \\
\text { on foot and by bicycle }\end{array}$ & Nodes per area & Blocks per area & Nodes per blocks \\
\hline Amsterdam & 51 & 360 & 54 & 7 \\
Barcelona & 34 & 269 & 55 & 5 \\
Bologna & 29 & 156 & 18 & 9 \\
Brussels & 28 & 252 & 47 & 5 \\
Budapest & 23 & 253 & 28 & 9 \\
Clermont Ferrand & 33 & 259 & 29 & 6 \\
Copenhagen & 39 & 142 & 22 & 7 \\
Dubai & 16 & 132 & 19 & 8 \\
Geneva & 34 & 223 & 27 & 7 \\
Glasgow & 24 & 244 & 35 & 10 \\
Graz & 35 & 196 & 20 & 8 \\
Lille & 31 & 197 & 25 & 7 \\
Lisbon & 24 & 264 & 38 & 8 \\
London & 31 & 451 & 53 & 5 \\
Lyons & 33 & 179 & 35 & 5 \\
Madrid & 26 & 323 & 59 & 10 \\
Manchester & 23 & 173 & 17 & \\
Marseilles & 34 & 197 & 23 & 17 \\
Moscow & 24 & 127 & & 9 \\
\hline
\end{tabular}




\begin{tabular}{lcccc}
\hline Cities & $\begin{array}{c}\text { Percentage of daily trips } \\
\text { on foot and by bicycle }\end{array}$ & Nodes per area & Blocks per area & Nodes per blocks \\
\hline Munich & 38 & 331 & 52 & 6 \\
Nantes & 23 & 336 & 32 & 10 \\
Newcastle & 27 & 178 & 19 & 9 \\
Oslo & 26 & 175 & 24 & 7 \\
Paris & 36 & 282 & 46 & 6 \\
Rome & 24 & 400 & 58 & 7 \\
Rotterdam & 42 & 365 & 62 & 6 \\
Seville & 42 & 305 & 53 & 6 \\
Singapore & 14 & 116 & 10 & 11 \\
Vienna & 30 & 268 & 46 & 6 \\
Warsaw & 20 & 179 & 20 & 9 \\
\hline
\end{tabular}

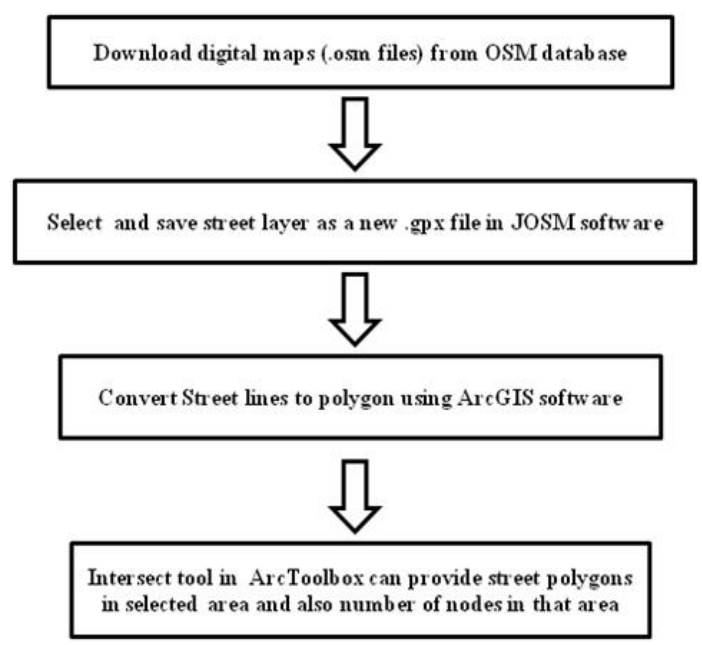

Figure 1 Converting OSM data to nodes per area, nodes per blocks and blocks per area

Since variables in this research have interval scales, the Pearson product-moment correlation coefficient (Pearson's correlation) is used to measure the strength and direction of the relationship between percentage of daily trips on food and by bicycle and each street network morphology indicators. A line best fit through the data is used by Pearson's correlation analysis to calculate Pearson correlation coefficient $(r)$ that shows the strength and direction of the relationship. This coefficient is between -1 and +1 . Negative values indicate negative relationship and positive values show positive association while zero means no association. The values that are closer to either +1 or -1 represent stronger association while the values that are closer to zero show weak relationship. The statistical significance of a correlation ( $p$-value) tests the null hypothesis that there is no relationship.

A linear association between the variables is assumed by Pearson's correlation. The scatter plots are used to test this assumption, significant outliers and Homoscedasticity. Since variables also should be approximately normally distributed, the variables are tested by Shapiro-Wilk normality test before Pearson's correlation analysis. The null hypothesis for ShapiroWilk normality test indicates that the sample is taken from a normal distribution, thus Sig $<0.05$ for ShapiroWilk Sig rejects the null hypothesis. This test is the most reliable normality test for small to medium sized samples [33-35]. Natural logarithm transformation is used for the variables that are not normally distributed. However, the normality is also tested after the transformation.

\subsection{RESULTS}

Pearson correlation coefficients are estimated to test the relationship between street network morphology indicators and percentage of daily trips on food and by bicycle. Table 2 indicates street network morphology indicators that are correlated with percentage of daily trips on food and by bicycle $(p<$ 0.05). Linear relationship, outliers and homoscedasticity are tested by scatter plots before Pearson correlation coefficients estimation. All variables except blocks per area are normally distributed after removing outliers (Refer Table 3). Table 4 shows the results of Shapiro-Wilk normality test for blocks per area after natural logarithm transformation. This variable is normally distributed after transformation.

The Pearson correlation coefficients are sorted from the highest to the lowest in Table 2. The bivariate correlation between natural logarithm of blocks per area and percentage of daily trips on food and by bicycle is $r(30)=0.530, p<0.003$. This correlation has the highest Pearson correlation coefficient among street network morphology indicators. The bivariate correlation between nodes per blocks and percentage of daily trips on food and by bicycle is $r(30)=-0.410, p<0.024$. All of street network morphology indicators except nodes per blocks have positive correlations with daily trips on food and by bicycle. The bivariate correlation between nodes per area and percentage of daily trips on foot and by bicycle is $r(30)=0.404, p<0.027$. This variable has the lowest Pearson correlation 
coefficient among street network morphology indicators.

Table 2 indicates that cities with higher blocks per area are associated with higher percentage of daily trips on food and by bicycle. More blocks mean more connectivity. Based on previously done studies, it is expected that connectivity produces more direct routes for alternative travel modes and increases trips on food and by bicycle. In addition, activity locations have shorter distances and there are more chances to use non-motorized transport modes when there are more blocks in an area. The Pearson correlation coefficient between percentage of daily trips by foot and bicycle and nodes per blocks shows that more trips by foot and bicycle are associated with fewer nodes per blocks. Nodes per blocks can indicate the morphological characteristic of the blocks and fewer nodes per blocks can be the result of simpler blocks with fewer nodes (intersections). Therefore, more but simpler blocks in an area lead to more trips on food and by bicycle. Table 2 also indicates that cities with higher nodes per area are associated with higher percentage of daily trips on food and by bicycle. Higher nodes per area also can represent connectivity that encourages people to have more walking and cycling trips.

Table 2 Pearson correlation coefficients

\begin{tabular}{lcccc}
\hline & \multicolumn{2}{c}{$\begin{array}{c}\text { Natural logarithm of } \\
\text { blocks per area }\end{array}$} & $\begin{array}{c}\text { Nodes per } \\
\text { Blocks }\end{array}$ & $\begin{array}{c}\text { Nodes per } \\
\text { area }\end{array}$ \\
\cline { 3 - 5 } & Pearson Correlation & .530 & -.410 & .404 \\
Percentage of daily trips on & & & \\
foot and by bicycle & Sig. (2-tailed) & .003 & .024 & .027 \\
& $\mathrm{~N}$ & 30 & 30 & 30 \\
\hline
\end{tabular}

Table 3 Normality test

\begin{tabular}{cccc}
\hline & \multicolumn{3}{c}{ Shapiro-Wilk } \\
\cline { 2 - 4 } Percentage of daily trips on foot and by bicycle & .977 & Statistic & Sig. \\
\cline { 2 - 4 } Blocks per area & .913 & 30 & .748 \\
Nodes per blocks & .938 & 30 & .018 \\
Nodes per area & .959 & 30 & .079 \\
\hline
\end{tabular}

Table 4 Normality test after transformation

\begin{tabular}{lccc}
\hline & \multicolumn{3}{c}{ Shapiro-Wilk } \\
\cline { 2 - 4 } Natural logarithm of blocks per area & Statistic & df & Sig. \\
\cline { 2 - 4 } & .936 & 30 & .073 \\
\hline
\end{tabular}

\subsection{DISCUSSION AND CONCLUSIONS}

The relationship between street network morphology and daily trips on foot and by bicycle is evaluated in this study. The results show that the natural logarithm of block density (blocks per area) and intersection density (nodes per area) have positive relationships with daily walking and cycling trips while more nodes per blocks lead to fewer trips on foot and by bicycle. Among these street network indicators, the natural logarithm of blocks per area has the highest positive coefficient so this variable can be more effective to have more daily trips on foot and by bicycle. The second effective indicator is nodes per blocks with negative relationship and nodes per area has the least positive coefficient, so it has the least effect on daily trips on foot and by bicycle.

There are some points that make this research significant. Firstly, there are very limited studies that consider city-level and compare various cities in different contexts since the scope of most of the previous efforts includes some cities in a country or some neighborhoods in a city. Therefore, this study tries to investigate the effects of street network morphology on the walking and cycling in various cities in different countries regardless of the context effects. In addition, although street network morphology can affect travel behavior significantly, there are limited studies regarding street network macro-level morphological effects. This study tries to evaluate these effects by considering some street network macro-level morphological indicators such as blocks per area, nodes per blocks and nodes per area.

Further studies can use the same scale (city-level in various countries) for other urban structure indicators and travel behavior variables to find effective factors toward sustainability at the city-level regardless of the context effects. These universal effective indicators can help to have some universal planning strategies. These universal strategies can be 
modified and localized for various contexts. Future studies also need to update their data sources regularly since some of urban structure indicators change rapidly. Open Street Map data source is used in this study. This data source includes free editable maps. Further studies can enhance the results by including original urban maps.

\section{Acknowledgement}

The authors wish to thank all of those who have supported this research for their useful comments during its completion. In particular, we would like to acknowledge the Universiti Teknologi Malaysia Research Management Centre (RMC) and Centre for Innovative Planning and Development (CIPD). The funding for this project is made possible through the research grant obtained from the Ministry of Education, Malaysia under the Fundamental Research Grant Scheme (FRGS) 2014 (FRGS grant no:R.J130000.7821.4F602).

\section{References}

[1] Who. 2010. World Health Statistics 2010. World Health Organization.

[2] Buehler, R., Pucher, J., Merom, D., and Bauman, A. 2011. Active Travel in Germany and the U.S.: Contributions of Daily Walking and Cycling to Physical Activity. American Journal of Preventive Medicine. 41 (3): 241-250.

[3] Asadi-Shekari, Z., Moeinaddini, M., and Zaly Shah, M. 2013a. Non-Motorized Level of Service Methods: Addressing Challenges in Research and Practice. Transport Reviews. 33(2): 166-194.

[4] Asadi-Shekari, Z., Moeinaddini, M., and Zaly Shah, M. 2013b. Disabled Pedestrian Level of Service Method for Evaluating and Promoting Inclusive Walking Facilities on Urban Streets. Journal of Transportation Engineering. 139(2): 181-192.

[5] Kuzmyak, R. J., and Pratt, R. H. 2003. TRB's Transit Cooperative Research Program (TCRP) Report 95: Chapter 15-Land Use and Site Design Provides Information on the Relationships Between Land Use/Site Design and Travel Behavior (No. 95). Washington D.C: Transportation Research Board.

[6] Morris, H. 2004. Commute Rates on Urban Trails: Indicators From the 2000 Census. Transportation Research Record. 1878: 116-121.

[7] Handy, S., Cao, X., and Mokhtarian, P. 2005. Correlation or Causality Between the Built Environment and Travel Behaviour? Evidence from Northern California. Transportation Research D. 10(6): 427-444.

[8] Moeinaddini, M., Asadi-Shekari, Z., Ismail, C. R., and Zaly Shah, M. 2013. A Practical Method for Evaluating Parking Area Level of Service. Land Use Policy. 33: 1-10.

[9] Moeinaddini, M., Asadi-Shekari, Z., and Zaly Shah, M. 2014a. The Relationship between Urban Street Networks and the Number of Transport Fatalities at the City Level. Safety Science. 62: 114-120.

[10] Moeinaddini, M., Asadi-Shekari, Z., and Zaly Shah, M. 2014b. Analyzing the Relationship between Park-andRide Facilities and Private Motorized Trips Indicators. Arabian Journal for Science and Engineering. 39(5): 34813488.

[11] Asadi-Shekari, Z., Moeinaddini, M., and Zaly Shah, M. 2014. A Pedestrian Level of Service Method for Evaluating and
Promoting Walking Facilities on Campus Streets. Land Use Policy. 38: 175-193.

[12] Moeinaddini, M., Asadi-Shekari, Z., and Zaly Shah, M. 2015. Analyzing the Relationships between the Number of Deaths in Road Accidents and the Work Travel Mode Choice at the City Level. Safety Science. 72: 249-254.

[13] Moeinaddini, M., Asadi-Shekari, Z., and Zaly Shah, M. 2015. An Urban Mobility Index for Evaluating and Reducing Private Motorized Trips. Measurement. 63: 30-40.

[14] Crawford, J. H. 2005. A Brief History of Urban Form Street Layout Through the Ages. First published on Carfree.com.

[15] Bento, A. M., Cropper, M. L. ,Mobarak, A. M., and Vinha K. 2005. The Effects of Urban Spatial Structure on Travel Demand in the United States. The Review of Economics and Statistics. 87(3): 466-478.

[16] Boarnet, M. G., Nesamani, K. S., and Smith, C. S. 2004. Comparing the Influence of Land Use on Nonwork Trip Generation and Vehicle Distance Traveled: An Analysis Using Travel Diary Data. 83rd Annual Meeting of the Transportation Research Board. Washington, DC.

[17] Cervero, R. and Kockelman, K. 1997. Travel Demand and the 3Ds: Density, Diversity, and Design. Transportation Research D. 2(3): 199-219.

[18] Pushkar, A. O., Hollingworth, B. J. and Miller, E. J. 2000. A Multivariate Regression Model for Estimating Greenhouse Gas Emissions from Alternative Neighborhood Designs. 79th Annual Meeting of the Transportation Research Board. Washington, DC.

[19] Ewing, R. Greenwald, M. J. Zhang, M. Walters, J. Feldman M. Cervero, R., and Thomas, J. 2009. Measuring the Impact of Urban Form and Transit Access on Mixed Use Site Trip Generation Rates-Portland Pilot Study. U.S. Environmental Protection Agency, Washington, DC.

[20] Frank, L. D. and Engelke, P. 2005. Multiple Impacts of the Built Environment on Public Health: Walkable Places and the Exposure to Air Pollution. International Regional Science Review. 28(2): 193-216.

[21] Frank, L. D., Kavage, S., Greenwald, M., Chapman, J., and Bradley, M. 2009. I-PLACE3S Health \& Climate Enhancements and Their Application In King County. King County HealthScape, Seattle, WA.

[22] Chatman, D. G. 2008. Deconstructing Development Density: Quality, Quantity and Price Effects on Household Non-Work Travel. Transportation Research Part A. 42(7): 1009-1031.

[23] Zhang, M. 2006. Travel Choice With No Alternative: Can Land Use Reduce Automobile Dependence? Journal of Planning Education and Research. 25(3): 31 1-326.

[24] Kulash, W., Anglin, J., and Marks, D. 1990. Traditional Neighborhood Development: Will the Traffic Work? Development. 21: 21-24.

[25] Alba, C. A., and Beimborn, E. 2005. Analysis of the Effects of Local Street Connectivity on Arterial Traffic. Transportation Research Board Annual Meeting. Washington, DC.

[26] Asadi-Shekari, Z., Moeinaddini, M., and Zaly Shah, M. 2015a. A Bicycle Safety Index for Evaluating Urban Street Facilities. Traffic Injury Prevention. 16: 283-288.

[27] Asadi-Shekari, Z., Moeinaddini, M., and Zaly Shah, M. 2015b Pedestrian Safety Index for Evaluating Street Facilities in Urban Areas. Safety Science. 74: 1-14.

[28] Boarnet, M. G., Joh, K. Siembab, W., Fulton, W., and Nguyen, M. T. 2011 . Retrofitting the Suburbs to Increase Walking: Evidence From a Land Use-Travel Study. Urban Studies. 48(1): 129-159.

[29] Joh, K., Boarnet, M. G., and Nguyen, M. T. 2009. Interactions Between Race/Ethnicity, Attitude, and Crime: Analyzing Walking Trips in the South Bay Area. 88th Annual Meeting of the Transportation Research Board. Washington, DC

[30] Targa, F., and Clifton, K. 2005. The Built Environment and Trip Generation for Non-Motorized Travel. Journal of Transportation and Statistics. 8(3): 55-70. 
[31] Bhat, C. R., Sen, S., and Eluru, N. 2009. The Impact of Demographics, Built Environment Attributes, Vehicle Characteristics, and Gasoline Prices on Household Vehicle Holdings And Use. Transportation Research B. 43(1): 1-18.

[32] Boer, R., Zheng, Y., Overton, A., Ridgeway, G. K. and Cohen, D. A. 2007. Neighborhood design and walking trips in ten U.S. metropolitan areas. American Journal of Preventive Medicine. 32(4): 298-304.
[33] Royston, P. 1982. Algorithm AS 181: TheWtest for normality. Applied Statistics. 31: 176-180.

[34] Sen, P. K., Jure ckov'a, and J, Picek, J. 2003. Goodness-ofFit Test of Shapiro-Wilk Type with Nuisance Regression and Scale. Austrian Journal of Statistics. 32(1/2): 163-177.

[35] Shapiro, S. S., and Wilk, M. B. 1965. An Analysis of Variance Test for Normality (Complete Samples). Biometrika. 52(3/4): $591-61$. 